\title{
Avaliação do crescimento das exportações do agronegócio gaúcho: uma aplicação do método constant-market-share
}

\author{
Evaluation of growth of exports of agribusiness in rio grande do sul: an application of the method constant-market-share \\ Carol Deitos Fries', Daniel Arruda Coronel², Kelmara Mendes Vieira³, Reisoli Bender Filho ${ }^{4}$ \\ ' Mestranda em Administração pela UFSM, Santa Maria, RS - Brasil \\ ${ }^{2.3 .4}$ Professor Adjunto do Departamento e do Programa de Pós-Graduação em Administração da UFSM - Santa Maria, RS - Brasil
}

\begin{abstract}
Resumo
O estado do Rio Grande do Sul é considerado um dos maiores produtores e exportadores brasileiros de produtos que compõem a cesta do agronegócio. Dentre os principais produtos exportados, destacam-se a soja em grão, as carnes e o fumo, sendo que os principais mercados de destino são a União Europeia, a China e a Rússia. O objetivo deste trabalho é identificar as fontes de crescimento das exportações gaúchas dos principais produtos da pauta exportadora, por meio do modelo Constant-Market-Share (CMS). Para isso, foram utilizados dados das exportações gaúchas e de exportações e importações mundiais, da União Europeia, da China e da Rússia, da soja em grão, carnes e fumo, no período de 2001 a 2010. De posse dos dados, dividiram-se as informações obtidas em três períodos: 2001 a 2004 (período I), 2005 a 2007 (período II) e 2008 a 2010 (período III). Os resultados indicaram que a principal fonte de crescimento para a soja em grãos, do período II em relação ao período I, foi o crescimento do comércio mundial; para o fumo e as carnes, foi a competitividade, e do período III em relação ao período II, foi o crescimento do comércio mundial para todos os produtos analisados.
\end{abstract}

Palavras-chave: Exportações gaúchas, soja, carne e fumo.

\begin{abstract}
The state of Rio Grande do Sul is considered one of the biggest producer and exporter of Brazilian products in agribusiness. Among the main product exports are: soy grain, meat and tobacco, in wich the main destination markets are the European Union, China and Russia. The aim of this work is to identify the sources of growth in these product exports through the model Constant Market Share (CMS). For this it was used data of exports in Rio Grande do Sul, global exports, European Union, China and Russia, soy grains, meat and tobacco in the period from 2001 to 2010. After that, the data were divided in three periods: 2001 to 2004 (period I), 2005 to 2007 (period II) and 2008 to 2010 (period III). The results indicated that the main source of growth for soy grains, comparing period II with period I was the growth of world trade, and the tobacco and the meat was the competitiveness, and period III with the period II was the growth of world trade for all products analyzed.
\end{abstract}

Keywords: Exports in Rio Grande do Sul, soy grain, meat and tobacco. 


\section{INTRODUÇÃO}

Em 2011, as exportações agrícolas brasileiras alcançaram U\$S 94,6 bilhões, e o superávit da balança comercial ficou em U\$S 77,5 bilhões de dólares. Além disso, a participação do agronegócio no Produto Interno Bruto (PIB) perfez 22\%, segundo o Ministério da Agricultura, Pecuária e Abastecimento (MAPA, 2012). Nos últimos anos, poucos países tiveram um crescimento tão expressivo no comércio internacional do agronegócio quanto o Brasil. O país se destaca como um dos líderes mundiais na produção e exportação de vários produtos agropecuários.

A crescente participação do país no mercado internacional é resultado da combinação de importantes fatores tais como o clima propício, o investimento em tecnologia, a disponibilidade de terras agricultáveis férteis e de alta produtividade, além do aproveitamento da mesma área para diversificar a produção.

Dentre os principais exportadores brasileiros de produtos agroindustriais, o estado do Rio Grande do Sul (RS) é um dos maiores produtores e exportadores do agronegócio, ocupando a quarta posição como maior exportador entre os estados da Federação, ficando apenas atrás de São Paulo, Minas Gerais e Rio de Janeiro. De acordo com a Secretaria de Comércio Exterior (SECEX, 2012), os principais produtos exportados, produzidos pelo estado, são a soja em grão, as carnes (bovina, suína e de frango) e o fumo, os quais representaram mais de $51 \%$ do total das exportações do agronegócio gaúcho, no período de 2010. E os principais mercados de destino são os países pertencentes à União Europeia, a China e a Rússia.

A produção de soja no Brasil é liderada pelos estados de Mato Grosso, com 29,2\% da produção nacional; Paraná com, 18,4\%; Rio Grande do Sul com 14,0\%, e Goiás, 10,8\%. O Ministério da Agricultura, Pecuária e Abastecimento (MAPA, 2012) estima uma produção de 88,9 milhões de toneladas de soja em grão para a safra de 2021/2022. Essa projeção é 17,8 milhões de toneladas a mais em relação ao que o Brasil produziu na safra de 2011/2012.

As estimativas indicam, também, que o Brasil pode manter a posição de primeiro exportador mundial de carne bovina e de frango. Segundo o Ministério da Agricultura (2012), até 2020, a expectativa é que a produção nacional de carnes suprirá $44,5 \%$ do mercado mundial. Já a carne de frango terá $48,1 \%$ das exportações mundiais, e a participação da carne suína será de $14,2 \%$.

Segundo Silva et al. (2011.b), os principais estados produtores de carne de frango são Paraná, Santa Catarina e Rio Grande do Sul, que, em 2007, tiveram uma participação de $23 \%, 17 \%$ e $15 \%$ na produção nacional, respectivamente. De acordo com a Associação Brasileira da Indústria Produtora e Exportadora de Carne Suína (ABIPECS, 2012), o estado é o segundo maior exportador de carne suína dentre os estados da federação, tendo exportado, em 2011, um volume de 162.600 toneladas.

Quanto ao fumo, o Rio Grande do Sul é o maior exportador dentre os estados da Federação, ao passo que o Brasil é o maior exportador do mundo. De acordo com o MAPA (2012), apesar da campanha contra o tabaco, os fumicultores gaúchos continuarão abastecendo o mercado internacional, enquanto não forem obrigados a parar, por lei ou por força da demanda, pois é uma atividade que proporciona uma alta rentabilidade.

Devido à importância que o crescimento das exportações do agronegócio gaúcho reflete na economia do país e às estimativas realizadas pelo Ministério da Agricultura, Pecuária e Abastecimento de que a participação do Rio Grande do Sul no comércio mundial deverá continuar relevante e com tendência de elevação, o presente estudo objetiva identificar as principais fontes de crescimento das exportações gaúchas quanto aos principais produtos da pauta exportadora, no período de 2001 a 2010, por meio do modelo Constant-Market-Share (CMS).

Este modelo permite decompor os principais indicadores das fontes de crescimento das exportações, em quatro efeitos, a saber: o crescimento do comércio mundial, a composição da pauta exportadora, o destino das exportações e a competitividade.

A análise com base no modelo CMS tem sua importância e interesse na medida em que determina o peso de cada efeito nas exportações do país em questão e mostra a extensão para a qual estas se direcionam para mercadorias e, ou mercados com maior potencial de expansão. Nesse sentido, os resultados poderiam indicar alternativas de atuação e sinalizar caminhos de distribuição das exportações, de forma a se perseguirem "market-shares" de maior dinamismo.

A relevância deste estudo se justifica pela possibilidade de ampliação do conhecimento sobre o comércio internacional do agronegócio, por meio da utilização de dados recentes sobre as exportações do setor. Também contribui para indicar quais os fatores que mais colaboraram para as exportações do agronegócio gaúcho e para quais mercados estão direcionadas as exportações.

O presente trabalho está estruturado em 
quatro seções, além desta introdução. Na segunda seção, tecem-se algumas considerações sobre a evolução das exportações gaúchas de soja em grão, carnes e fumo. Na terceira, é apresentado o referencial analítico e descrito o modelo CMS. $\mathrm{Na}$ quarta, os resultados obtidos são analisados e discutidos e, concluindo, são delineadas algumas considerações finais sobre o tema discutido.

\section{EVOLUÇÃO DAS EXPORTAÇÕES GAÚ- CHAS}

Em 2011, as exportações gaúchas alcançaram um crescimento de $26,3 \%$, em dólares correntes, em relação ao resultado do ano anterior. De acordo com a Fundação de Economia e Estatística (FEE, 2012), o volume das exportações para o Rio Grande do Sul foi de 9,6\%, superior ao esperado pela Organização Mundial do Comércio, de $5,8 \%$. No entanto, esse resultado foi razoável, se comparado à média nacional, que foi de $26,8 \%$. Esses dados mantiveram o estado em quarto lugar entre os maiores exportadores do país, ficando atrás de São Paulo, Minas Gerais e Rio de Janeiro.

Tabela 1 - Participação do Agronegócio no Total das Exportações do Rio Grande do Sul, no período de 2005 a 2011

\begin{tabular}{lccc}
\hline Ano & $\begin{array}{c}\text { Exportações } \\
\text { Agro }\end{array}$ & $\begin{array}{c}\text { Exportações } \\
\text { Totais }\end{array}$ & $\begin{array}{c}\text { Part. } \\
\text { (\%) Exp. } \\
\text { Agro }\end{array}$ \\
$\mathbf{2 0 0 5}$ & 5.932 & 10.476 & 57 \\
$\mathbf{2 0 0 6}$ & 6.953 & 11.802 & 59 \\
$\mathbf{2 0 0 7}$ & 8.829 & 15.018 & 59 \\
$\mathbf{2 0 0 8}$ & 10.636 & 18.385 & 58 \\
$\mathbf{2 0 0 9}$ & 9.042 & 15.236 & 59 \\
$\mathbf{2 0 1 0}$ & 9.309 & 15.382 & 61 \\
$\mathbf{2 0 1 1} *$ & 10.651 & 16.698 & 64 \\
\hline
\end{tabular}

Fonte: Organização dos autores a partir de dados do Mdic Alice Web (2012).

${ }^{*}$ ) Até Outubro

Cerca de $64 \%$ das exportações do Rio Grande do Sul, até outubro de 2011, foram de produtos que compõem a cesta do Agronegócio, superando todo o ano de 2010 e atingindo US\$ 10,6 bilhões de um total de US\$ 16,7 bilhões exportados pelo estado.

De acordo com a Tabela 2, a soja, as carnes e o fumo lideram as exportações do agronegócio gaúcho. Segundo a Federação da Agricultura do
Estado do Rio Grande do Sul (Sistema FARSUL, 2012), o complexo soja liderou as exportações em 2011, representando 40\% das exportações do Agronegócio. Em segundo lugar está o complexo carnes, que representou 19\% das exportações do Agronegócio e cresceu 6,9\%, puxado pelo aumento da carne bovina no mercado internacional. O complexo fumo, apesar da safra maior em 2010, não refletiu o crescimento de safra no valor exportado, mantendo-se estável em relação ao mesmo período de 2010.

O estado é considerado um dos maiores produtores e exportadores de grãos do Brasil, sendo responsável por aproximadamente $15 \%$ da produção nacional de soja. No ano agrícola 2010/2011, foram produzidas mais de $11.000 \mathrm{mil}$ toneladas de acordo com a Companhia Nacional de Abastecimento (CONAB, 2012).

As exportações gaúchas de soja em grão, no ano de 2011, tiveram um desempenho substantivo, visto que foram comercializados, aproximadamente, US $\$ 3,0$ bilhões desse produto, um aumento de $66,1 \%$ em relação ao ano anterior. Segundo a Fundação de Economia e Estatística (FEE, 2012), essa expansão deveu-se, principalmente, ao aumento dos preços do grão, da ordem de $32,6 \%$, embora o volume também tenha apresentado uma elevação expressiva de $25,3 \%$.

O clima é fator decisivo para o bom desempenho das exportações de soja do estado, porém, não foi o único responsável por este expressivo crescimento. Com a fronteira agrícola esgotada há muito tempo, os sojicultores veem, nos ganhos de produtividade, a maior possibilidade de aumentar o volume colhido. A cada ano eles utilizam novas técnicas, mais avançadas, como sementes certificadas, correção do solo, variedades resistentes a pragas e doenças, assim como o uso de fertilizantes e máquinas modernas.

No entanto, um dos fatores que impulsionaram as exportações de soja em grão foi a Lei Kandir, de 13 de setembro de 1996, que desonerou as exportações de produtos in natura do Imposto sobre Circulação de Mercadorias (ICMS), e também a desvalorização cambial de 1999 (CORONEL, MACHADO E CARVALHO, 2008).

Outro fator que favoreceu o crescimento das exportações, de acordo com a FEE (2012), foram os estoques ajustados dos Estados Unidos, maior exportador mundial de soja, ao mesmo tempo em que a Argentina, terceira maior exportadora, apresentou safra inferior em 2011. Dessa forma, abriu-se mais espaço aos produtos brasileiros no mercado externo.

Por outro lado, continuou aquecida a 
Tabela 2 - Produtos mais exportados pelo Rio Grande do Sul no período de 2010 a 2011.

\begin{tabular}{l|r|r|r}
\hline \multicolumn{1}{c|}{ Produtos } & \multicolumn{1}{c|}{$\mathbf{2 0 1 0}$} & \multicolumn{1}{c}{$\mathbf{2 0 1 1}$} & Var (\%) \\
\hline Complexo soja & 2.715 .681 .008 & 4.238 .542 .797 & 56.1 \\
Complexo carnes & 1.852 .894 .498 & 1.980 .356 .201 & 6.9 \\
Complexo fumo & 1.662 .174 .552 & 1.662 .113 .649 & 0,0 \\
Cereais, farinhas e preparações & 217.767 .406 & 945.100 .198 & 334,0 \\
Couros, produtos de couro e peleteria & 836.664 .662 & 771.331 .826 & -7.8 \\
Complexo florestal & 411.257 .520 & 432.615 .103 & 5.2 \\
Demais produtos de origem vegetal & 87.443 .118 & 115.425 .701 & 32,0 \\
Demais produtos de origem animal & 67.909 .311 & 66.231 .493 & -2.5 \\
Produtos alimentícios diversos & 41.066 .129 & 59.011 .024 & 43.7 \\
Demais produtos & 183.265 .889 & 238.865 .129 & 30.3 \\
\hline TOTAL & $\mathbf{8 . 0 7 6 . 1 2 4 . 0 9 3}$ & $\mathbf{1 0 . 5 0 9 . 5 9 3 . 1 2 1}$ & $\mathbf{3 0 . 1}$ \\
\hline
\end{tabular}

Tabela 3 - Evolução das exportações de soja em grão, carnes e fumo (US\$ em mil e peso líquido em toneladas) do Rio Grande do Sul no período de 2001 a 2011.

\begin{tabular}{l|r|r|r|r|r|r|r|r|r}
\hline \multirow{2}{*}{ Período } & \multicolumn{3}{|c|}{ Soja em Grão } & \multicolumn{3}{c|}{ Fumo } & \multicolumn{3}{c}{ Carnes } \\
\cline { 2 - 10 } & $\begin{array}{l}\text { US\$ FOB } \\
\text { (em mil) }\end{array}$ & $\begin{array}{r}\text { Variação } \\
\text { US\$ (\%) }\end{array}$ & \multicolumn{1}{c|}{$\begin{array}{c}\text { Peso } \\
\text { Líquido (t) }\end{array}$} & $\begin{array}{c}\text { US\$ FOB } \\
\text { (em mil) }\end{array}$ & $\begin{array}{r}\text { Variação } \\
\text { US\$ (\%) }\end{array}$ & $\begin{array}{c}\text { Peso } \\
\text { Líquido (t) }\end{array}$ & $\begin{array}{c}\text { US\$ FOB } \\
\text { (em mil) }\end{array}$ & $\begin{array}{r}\text { Variação } \\
\text { US\$ (\%) }\end{array}$ & \multicolumn{1}{c}{$\begin{array}{c}\text { Peso } \\
\text { Líquido (t) }\end{array}$} \\
\hline $\mathbf{2 0 0 1}$ & 484.581 & 0 & 2.841 .160 & 806.823 & 0 & 378.087 & 228.406 & 0 & 229.183 \\
$\mathbf{2 0 0 2}$ & 348.331 & -28.12 & 1.796 .926 & 869.054 & 7.71 & 412.597 & 229.646 & 0.54 & 288.262 \\
$\mathbf{2 0 0 3}$ & 840.162 & 141.20 & 3.792 .297 & 942.483 & 8.45 & 416.211 & 349.804 & 52.32 & 371.246 \\
$\mathbf{2 0 0 4}$ & 631.761 & -24.80 & 2.200 .352 & 1.225 .262 & 30.00 & 514.709 & 470.036 & 34.37 & 414.922 \\
$\mathbf{2 0 0 5}$ & 107.779 & -82.94 & 439.739 & 1.424 .363 & 16.25 & 535.641 & 618.323 & 31.55 & 420.113 \\
$\mathbf{2 0 0 6}$ & 739.244 & 585.89 & 3.281 .005 & 1.201 .274 & -15.66 & 426.718 & 913.463 & 47.73 & 493.414 \\
$\mathbf{2 0 0 7}$ & 1.605 .973 & 117.25 & 5.503 .371 & 1.615 .651 & 34.49 & 524.045 & 951.353 & 4.15 & 493.686 \\
$\mathbf{2 0 0 8}$ & 1.617 .907 & 0.74 & 3.516 .357 & 1.875 .933 & 16.11 & 487.990 & 1.312 .952 & 38.01 & 560.886 \\
$\mathbf{2 0 0 9}$ & 1.936 .782 & 19.71 & 4.858 .823 & 2.071 .991 & 10.45 & 459.396 & 1.037 .354 & -20.99 & 607.308 \\
$\mathbf{2 0 1 0}$ & 1.782 .456 & -7.97 & 4.685 .338 & 1.767 .761 & -14.68 & 328.613 & 1.223 .170 & 17.91 & 619.490 \\
$\mathbf{2 0 1 1}$ & 2.961 .372 & 66.14 & 5.869 .070 & 1.852 .354 & 4.79 & 360.719 & 1.157 .474 & -5.37 & 524.037 \\
\hline
\end{tabular}

Fonte: Organização dos autores a partir de dados do Mdic Alice Web (2012).

demanda chinesa por grãos de soja, que, transformados, servem de ração para alimentar suínos e aves e, assim, garantir a alimentação de milhões de chineses, que, a cada ano, se dirigem aos centros urbanos em busca de melhores condições de vida.

Esses fatores vêm viabilizando o melhor desempenho das exportações de soja do Rio Grande do Sul. No entanto, ainda segundo a FEE (2012), a manutenção do real valorizado não permitiu aos sojicultores gaúchos o benefício completo dessa conjuntura internacional favorável. E um dos grandes desafios que o governo enfrenta, em relação às exportações, segundo a Secex (2012), são as barreiras tarifárias e não tarifárias que os principais importadores de soja impõem.
A cada ano, a participação gaúcha no comércio internacional de carnes também vem crescendo, com destaque para a produção de carne bovina, suína e de frango (MAPA, 2012).

$\mathrm{O}$ comércio exterior de carnes in natura (carnes e miudezas, comestíveis), pelo Rio Grande do Sul, atingiu, ao longo de 2010, o valor de US\$ 1,2 bilhões, com crescimento de $17,9 \%$ sobre o verificado no ano anterior; no entanto, no ano de 2011, as exportações diminuíram em quase 5\% de acordo com o Ministério do Desenvolvimento, Indústria e Comércio (MDIC, 2012). Preponderaram as exportações de aves, basicamente carne de frango (fresca, refrigerada ou congelada), secundadas pelas vendas externas de carne suína (fresca, 
refrigerada ou congelada) (FEE, 2012).

Como mencionado anteriormente, as barreiras não tarifárias têm ganhado importância como fator de restrição ao fluxo do comércio internacional. Segundo Machado et al. (2006), no mercado mundial de carne bovina, destacam-se as barreiras sanitárias, que restringem a comercialização da carne in natura.

A cadeia produtiva de carne bovina, segundo Malafaia e Barcellos (2007), vem enfrentando constantes dificuldades, decorrentes da falta de subsídios para nortear o setor de forma sistêmica. Não obstante a isso, o Rio Grande do Sul é considerado o quarto maior produtor de carne bovina do país.

As exportações de carne de aves alcançaram, em 2011, o valor de US\$1,3 bilhão, aumento de $8,0 \%$ sobre o anterior e a carne de frango liderou mais de $50 \%$ dessas exportações. Esse desempenho positivo deveu-se, exclusivamente, à recuperação dos preços desse produto no mercado internacional.

Já as vendas externas de carne suína do estado atingiram, em 2011, segundo a Associação Brasileira da Indústria Produtora e Exportadora de Carne Suína (ABIPECS, 2012), o valor de US\$ 474 milhões, resultado este aquém do obtido no ano anterior, que foi de US\$ 544 milhões. Esse desempenho deveu-se, exclusivamente, à queda do volume exportado, de 207.591 toneladas em 2010 para 162.600 toneladas em 2011, não compensado pelo crescimento dos preços.

A performance das exportações de carne suína do Rio Grande do Sul era razoável até meados de junho de 2011, conforme a FEE (2012). No entanto, neste mesmo ano, o principal importador desse produto, a Rússia, decretou um embargo às empresas fornecedoras dos estados do Mato Grosso, Paraná e Rio Grande do Sul, alegando motivos sanitários. Essa medida atingiu sobremaneira as vendas externas do estado, uma vez que aquele país euroasiático costumava comprar cerca de $80 \%$ da produção gaúcha comercializada no exterior.

Quanto ao tabaco, a agricultura familiar de parte da região Sul do Brasil é responsável por $96 \%$ da produção brasileira, sendo que, conforme Arend, Begnis e Alievi (2012), parte desta produção está centrada em 327 dos 496 municípios do Rio Grande do Sul.

A produção de tabaco no mundo mantém-se estabilizada em torno de 6,5 milhões de toneladas, refletindo uma demanda que tende a cair nos países desenvolvidos e a estabilizar-se, ou mesmo aumentar, naqueles em desenvolvimento ou subdesenvolvidos (FEE, 2012). Neste sentido, haverá demanda, por muito tempo, por cigarros e, enquanto não forem obrigados, por lei ou por força da demanda, a reduzir ou a interromper seu cultivo, os fumicultores deverão continuar abastecendo o mercado internacional.

De acordo com os dados do Ministério do Desenvolvimento, Indústria e Comércio (MDIC, 2012), as exportações gaúchas de tabaco não manufaturado, nos últimos anos, mantêm-se em torno de US\$ 2 bilhões ao ano. Em 2011, foram exportadas 360 mil toneladas, um aumento de aproximadamente $10 \%$ em relação ao ano anterior, apesar de representar uma queda de quase $5 \%$ nos preços neste período, isto devido à queda do volume exportado em 2010.

No entanto, a exportação de fumo, apesar de também estar sujeita às variações climáticas, depende mais da evolução da demanda mundial que, atualmente, está estagnada. E, com a divulgação cada vez maior dos malefícios do cigarro, essa demanda não deverá crescer a ponto de apresentar num salto expressivo das vendas externas desse produto.

Por outro lado, a demanda da soja em grão vem crescendo. De acordo com a Tabela 3, o Rio Grande do Sul exportou, em 2011, 5,8 milhões de toneladas de soja em grão, representando $25 \%$ a mais do volume exportado no ano anterior. $\mathrm{O}$ período de maior baixa foi em 2005, no qual foram exportadas apenas 439 mil toneladas.

Em se tratando de carnes, representadas neste estudo por carne bovina, suína e de frango, houve uma queda de $15 \%$ do volume exportado em 2011, devido ao aumento relativo dos preços neste período. O comércio exterior de carnes do estado nos últimos anos atingiu US\$ 1,2 bilhões.

O fumo mostra uma tendência estável, confirmando os dados da Fundação de Economia e Estatística sobre a estabilização da produção e comercialização deste produto. Dessa forma, a Tabela 3 apresenta uma variação positiva do valor US\$ exportado devido principalmente ao aumento significativo dos preços dessa commoditie.

\section{REFERENCIAL ANALÍTICO}

\section{I Modelo constant market share}

De acordo com Carvalho (1995), os trabalhos e pesquisas baseados em modelos Constant-Market-Share têm como objetivo avaliar a participação de um país ou região no fluxo mundial ou regional de comércio e desagregar as tendências de crescimento das exportações e ou importações de acordo com seus determinantes.

O pressuposto básico do modelo é que cada 
país ou bloco mantenha constante sua parcela no comércio mundial. Se houver alteração nesta parcela, ela deve estar implícita no modelo, e sua performance é atribuída à competitividade, associada aos preços relativos (LEAMER; STERN, 1970).

Os fatores que colaboram para que as exportações de um país não acompanhem a média mundial, de acordo com Leamer e Stern (1970), são concentração das exportações em mercadorias cuja demanda cresça mais lentamente que a média dos produtos; exportações destinadas a regiões estagnadas; e falta de vontade ou de condições de o país competir com os seus ofertantes no mercado internacional.

Da mesma forma, Machado et al. (2006) afirmam que este modelo permite determinar os fatores que influenciam o desempenho das exportações de um país ao longo dos anos. O crescimento favorável ou desfavorável do setor exportador é atribuído à estrutura das exportações do país e à sua competitividade. A principal vantagem deste método é permitir a análise, por componentes e pelo comportamento, do produto no mercado de destino.

Neste sentido, o modelo CMS tem sido utilizado, em diversos estudos, para análises da determinação dos fatores que contribuíram para o desempenho das exportações de um país em determinado período. Dentre eles, destacam-se Carvalho (1995), Figueiredo, Santos e Lírio (2004), Machado et al. (2006), Coronel, Machado e Carvalho (2008), e Silva et al. (2011.a).

$\mathrm{Na}$ formulação específica do modelo CMS, conforme Leamer e Stern (1970), para representá-lo matematicamente, considera-se como variável básica o valor das exportações. Primeiramente, parte-se das exportações não diferenciadas por mercadorias e regiões, de modo que se pode escrever a seguinte identidade:

$\mathrm{V}^{\prime} . .-\mathrm{V} . .=\mathrm{rV}+\left(\mathrm{V}^{\prime} . .-\mathrm{V} . .-\mathrm{rV} ..\right)$

$\mathrm{V}$.. = valor total das exportações do país ou região $\mathrm{A}$, no período (I);

$\mathrm{V}^{\prime} .$. . = valor total das exportações do país ou região $\mathrm{A}$, no período (II);

$r=$ mudança percentual nas exportações mundiais do período (I) para o período (II)

A Identidade (1) expressa a variação das exportações do país ou região A, do período (I) para o período (II), associada ao incremento das exportações mundiais (a) e a um efeito residual atribuído à competitividade.

Considerando-se que as exportações são compostas por um conjunto diverso de mercadorias, tem-se para a i-ésima mercadoria, a seguinte expressão:

$$
\mathrm{V}^{\prime} \text { i. }-\mathrm{Vi} .=\text { riVi }+\left(\mathrm{Vi}^{`} \text {. }-\mathrm{V} .-\mathrm{riVi} .\right)
$$

em que:

Vi. = valor das exportações da mercadoria

(i) do país ou região A no período (I);

V'i. = valor das exportações da mercadoria

(i) do país ou região A no período (II);

ri = mudança percentual nas exportações mundiais da mercadoria (i) para o país ou região (j) do período (I) para o período (II).

A Expressão (2) pode ser agrupada em:

V'i.. - Vi.. = riVi. + (Vi '. $-\mathrm{Vi} .-\mathrm{riVi}.)=$

$(\mathrm{rV}$.. $)+\Sigma(\mathrm{ri}-\mathrm{r}) \mathrm{Vi} .+\Sigma(\mathrm{Vi}$.. - Vi.-riVi.)

(a)

(b)

(c)

Com base na Equação (3), pode-se inferir que o crescimento das exportações do país A está relacionado com (a) crescimento das exportações mundiais, (b) pauta das exportações do país ou região A no período (I) e ao efeito residual oriundo da diferença entre a variação efetiva e a variação esperada nas exportações de cada grupo de bens.

Ainda nessa perspectiva, a desagregação do modelo CMS considera tanto a diferenciação por tipo de mercadoria comercializada quanto por países ou regiões de destino (j):

$V{ }^{\prime} i j-V i j=r i j V i j+(V ' i j-V i j-r i j-V i j)$

em que:

Vij = valor das exportações da mercadoria (i) do país ou região A para o país ou região (j) no período (I);

$V^{\prime} \mathrm{ij}=$ valor das exportações da mercadoria (i), do país ou região A para o país ou região (j) no período (II);

rij = mudança percentual nas exportações mundiais da mercadoria (i) para o país ou região (j), do período (I) para o período (II).

Desagrupando e reajeitando os termos, tem-se a seguinte Identidade (5):

$V^{\prime} . .-V \Sigma i \Sigma j r i j V i j+\Sigma i \Sigma j\left(V^{\prime} i j-V i j-r i j i j\right)=$ rV.. $+\sum \mathrm{i}(\mathrm{ri}-\mathrm{r}) \mathrm{Vi} .+\sum \mathrm{i} \Sigma \mathrm{j}(\mathrm{rij}-\mathrm{ri}) \mathrm{Vij}$
(a)
(b)
$+\Sigma i \Sigma j\left(V^{\prime} i j-V i j-r i j V i j\right)$

(c)

(d)

A Identidade (5) permite decompor a taxa de crescimento das exportações do país A em quatro efeitos, a saber:

a) efeito crescimento do comércio mundial: aumento observado se as exportações do país 
tiveram crescido à mesma taxa de crescimento do comércio mundial, ou seja, o crescimento das exportações ocorre devido ao crescimento mundial das exportações;

b) efeito composição da pauta: mudança na estrutura da pauta com concentração em mercadorias com maior crescimento da demanda, ou seja, aumento devido à composição das exportações do país. Neste caso, o efeito composição da pauta será positivo se as exportações estiverem concentradas em mercadorias de maior expansão ou quando a taxa de crescimento for superior à mundial. Tendo em vista que, neste trabalho, abordou-se o desempenho individual de cada setor do agronegócio gaúcho, este efeito é considerado igual a zero;

c) efeito destino das exportações: mudanças decorrentes das exportações de mercadorias para mercados de crescimento mais ou menos dinâmicos, ou seja, crescimento decorrente da distribuição do mercado de exportação do país;

d) efeito residual, representando competitividade: o resíduo reflete a diferença entre o crescimento efetivo das exportações e o que teria ocorrido nas exportações do país se a participação de cada bem, para os mercados compradores, tivesse sido mantida. A medida deste efeito residual está relacionada com as mudanças nos preços relativos, ou seja, os importadores tendem a substituir o consumo dos bens cujos preços se elevam pelo consumo daqueles com preços relativos menores.

$\mathrm{O}$ efeito competitividade (d) $\Sigma \Sigma(\mathrm{V}$ 'ij rijVij) significa que uma economia é competitiva na produção de determinada commodity quando consegue pelo menos igualar-se aos padrões de eficiência vigentes no resto do mundo quanto à utilização de recursos e à qualidade do bem. A diferença entre o crescimento das exportações verificado pelo modelo CMS e o crescimento efetivo das exportações é atribuída ao efeito competitividade. A medida

deste efeito está relacionada com mudanças nos preços relativos.

Neste sentido, quando um país deixa de manter sua parcela no mercado mundial, o termo competitividade torna-se negativo e indica o fracasso do país em manter sua parcela no mercado mundial, como também que os preços estão aumentando para o país em questão, em proporção maior que seus competidores, ou seja, os importadores tendem a substituir o consumo das commodities cujos preços se elevaram pelo consumo daqueles com preços menores em termos relativos.

Conforme Leamer e Stern (1970), o efeito competitividade, além dos preços relativos, recebe influência de outros fatores tais como mudanças tecnológicas, medidas de incentivo, maiores ações de marketing, aprimoramento dos mecanismos de financiamento e crédito e habilidade para atender com prontidão as encomendas dos importadores.

Leamer e Stern (1970) e Rigauz (1971) apontam várias críticas ao modelo Constant-Market-Share, visto que o mesmo incorpora somente os determinantes pelo lado da demanda nas relações mundiais de comércio, desconsiderando os fatores da oferta, sendo que as relações econômicas de comércio são determinadas pela interação de oferta e demanda. Não obstante a isso, essa visão unilateral do modelo de certa forma é minimizada pelo efeito competitividade, visto que os preços refletem a interação da oferta e demanda.

\subsection{Mercado de destino}

Consideraram-se, neste estudo, os mercados que absorveram a maior parte das exportações gaúchas de soja em grão, carnes e fumo:

a) Soja em grão: China, União Europeia e o resto do mundo (representando os demais importadores);

b) Carnes: União Europeia, Rússia e o resto do mundo (representando os demais importadores);

c) Fumo: União Europeia, China e o resto do mundo (representando os demais importadores).

\subsection{Fonte de dados e período de análise}

Foram obtidos junto ao Sistema de Análise das Informações de Comércio Exterior (ALICE) e da Secretária de Comércio Exterior (SECEX), dados de exportações gaúchas Free on Board (FOB) em dólares, e junto ao United Nations Commodity Trade Statistics Database (Un Comtrade) dados, em dólares, de exportações e importações mundiais, da União Europeia, China e Rússia, no período de 2001 a 2010. Os dados coletados foram identificados pelos seguintes códigos NCM: 1201 (soja em grão), 2401 (tabaco não manufaturado), 020130, 020230, 020319, 020329, 020711, 020712 (carne bovina, suína e de frango).

De posse deles, dividiram-se as informações obtidas em períodos, uma vez que o modelo CMS é fixado em pontos discretos no tempo. $\mathrm{O}$ principal critério para a divisão dos períodos para análise, neste estudo, foram os que apresentaram mudanças na política econômica, a qual impactou no agronegócio.

De acordo com Carvalho (1995), a divisão em períodos mais curtos permite verificar com maior segurança as alterações mais frequentes que ocorreram entre um dado período analisado.

Dessa forma, dividiu-se o período em três 
subperíodos:

a) Primeiro período - 2001 a 2004: representa o final do governo de Fernando Henrique Cardoso e o início do primeiro mandato do governo Lula, onde se observou a manutenção da mesma política macroeconômica do governo anterior.

b) Segundo período - 2005 a 2007: representa o início do segundo mandato do governo Lula, onde se observou algumas alterações na política macroeconômica, com um caráter de cunho desenvolvimentista.

c) Terceiro período - 2008 a 2010: representa o período de maior intensidade da crise econômica mundial, a qual afetou o comércio mundial.

\section{ANÁLISE E DISCUSSÃO DOS RESULTA- DOS}

As análises foram desenvolvidas considerando a divisão dos períodos apresentada anteriormente.

\section{I Decomposição das fontes de crescimento da soja em grão}

a) período II em relação ao período I

A participação média do Rio Grande do Sul no total mundial comercializado da soja em grão, de acordo com a Tabela 4, passou do período I $(2001 / 2004)$ para o período II $(2005 / 2007)$ de $4,43 \%$ para $4,49 \%$. Embora esta variação seja relativamente pequena, pode ser observado um crescimento das exportações gaúchas em todos os períodos, visto que, do período I para o período II, o aumento foi de, aproximadamente, $42 \%$, atingindo um montante de US\$ 817 milhões comercializados. Dessa forma, os dados confirmam o aumento da participação do estado no comércio mundial.

As análises das exportações gaúchas de soja em grão indicam que, em todos os períodos, os maiores importadores do produto foram a União Europeia e a China.

O principal fator explicativo das exportações gaúchas de soja em grão, conforme a Tabela 5 , foi o efeito crescimento do comércio mundial com $156,94 \%$, sendo que os efeitos destino das exportações e competitividade foram negativos.

O efeito crescimento do comércio mundial pode ser explicado pelo aumento de $40 \%$ das exportações mundiais, devido, de certa forma, ao aumento significativo da demanda de grãos pela China e à recessão dos Estados Unidos, em 2001, que resultou em quebras sucessivas das safras.

De acordo com Souza (2007), a quebra da safra americana incentivou o aumento da produção de soja no Brasil, no período de 2002 e 2003.

Tabela 4 - Valor médio das exportações mundiais e gaúchas de soja em grão, em US\$, e participação do Rio Grande do Sul nas exportações mundiais $(2001 / 2010)$

\begin{tabular}{l|c|c|c}
\hline & $\begin{array}{c}\text { PI - 2001 a } \\
\mathbf{2 0 0 4}\end{array}$ & $\begin{array}{c}\text { P II - 2005 a } \\
\mathbf{2 0 0 7}\end{array}$ & $\begin{array}{c}\text { P III - 2008 a } \\
\mathbf{2 0 1 0}\end{array}$ \\
\hline $\begin{array}{l}\text { Export. } \\
\text { Mundiais }\end{array}$ & 13.008 .393 .566 & 18.202 .227 .817 & 35.709 .774 .431 \\
$\begin{array}{l}\text { Export. } \\
\text { Gaúchas } \\
\text { Market }\end{array}$ & 576.208 .695 & 817.665 .301 & 1.779 .048 .507 \\
Share (\%) & 4.43 & 4.49 & 4.98 \\
\hline
\end{tabular}

Fonte: Organização dos autores a partir de dados do Mdic Alice Web e Un Comtrade (2012).

Tabela 5 - Fontes de crescimento das exportações gaúchas de soja em grão $(2001 / 2010)$

\begin{tabular}{lcc}
\hline & P II - P I & P III - P II \\
$\begin{array}{l}\text { Crescimento do } \\
\text { comércio mundial }\end{array}$ & 156.94 & 49.75 \\
$\begin{array}{l}\text { Destino das } \\
\text { exportações }\end{array}$ & -5.50 & 42.82 \\
Competitividade & -51.40 & 7.40
\end{tabular}

Fonte: Organização dos autores a partir de dados do Mdic Alice Web e Un Comtrade (2012).

O efeito destino das exportações, apesar de ser negativo, não foi alto, em valor absoluto, e isso indica o baixo dinamismo de mercado, ou seja, o Rio Grande do Sul está direcionando suas exportações para mercados menos dinâmicos que a média do comércio mundial.

A competitividade teve efeito negativo, de $51,4 \%$, nas exportações de grãos. Pode estar relacionada com a sobrevalorização do câmbio, que começou a partir de 2003, resultando no aumento dos preços do grão no comércio internacional.

Diante da recuperação da safra norte-americana e da valorização do câmbio, de acordo com Souza (2007), os agricultores brasileiros perdem competitividade, pois não recebem grandes subsídios do governo, não têm um mercado de crédito bem desenvolvido, operam numa economia com altos juros, elevados custos de frete até os distantes portos, entre outros fatores.

b) período III em relação ao período II

Quando se analisa a participação média do Rio Grande do Sul no total mundial comercializado da soja em grão, no período II $(2005 / 2007)$ para o período III $(2008 / 2010)$, de acordo com a Tabela 4, observa-se um aumento de apenas $0,49 \%$. 
Porém as exportações gaúchas apresentaram um expressivo crescimento de, aproximadamente, $118 \%$, atingindo uma média de US $\$ 1,7$ bilhões comercializados no período 2008/2010.

A decomposição das fontes de crescimento, do período III em relação ao período II, de acordo com a Tabela 5, indica que o efeito crescimento do comércio mundial continuou sendo importante, porém sofreu uma redução, passando a ser responsável por $49,75 \%$ das exportações de grãos de soja. Essa redução pode estar relacionada à crise econômica internacional que provocou mudança nas exportações brasileiras.

Nesse contexto, a crise também desempenhou um papel catalisador no fortalecimento da China enquanto principal destino das exportações, o que se pode relacionar ao aumento do efeito destino das exportações, que, neste período, foi positivo, 42,82\%. De acordo com Corrêa (2009), dentre os cinco maiores parceiros comerciais, a China foi o único país que registrou aumento nas importações oriundas do Brasil.

Por outro lado, pode significar que as exportações de grãos de soja do Rio Grande do Sul estão se concentrando em mercados mais dinâmicos, indicando que a taxa das importações dos mercados importadores do Rio Grande do Sul está crescendo a taxas maiores que a média do mercado mundial.

Assim como os efeitos crescimento do comércio mundial e destino das exportações foram positivos no período, a competitividade passou a contribuir com $7,4 \%$ para as exportações do estado. A competitividade da soja em grão foi favorecida pelo aumento da produtividade e produção nos últimos anos.

\subsection{Decomposição das fontes de crescimento do fumo}

a) Período II em relação ao período I

De acordo com a Tabela 6, o estado do Rio Grande do Sul, no primeiro período, representava $16,46 \%$ das exportações mundiais de tabaco não manufaturado (fumo) e teve um aumento de 2,1\% no período posterior, alcançando US\$ 1,4 bilhões nas exportações desta commoditie. Um percentual bastante significativo a nível mundial.

Assim como a soja, os principais mercados de destino que embarcam a maior parte do tabaco não manufaturado, produzido no Rio Grande do Sul, são a União Europeia e a China.

A decomposição das fontes de crescimento do fumo, do período II (2005/2007) em relação ao período I (2001/2004), de acordo com a Tabela 7 , mostra que os efeitos crescimento do comér- cio mundial e competitividade foram positivos, enquanto que o efeito destino das exportações foi negativo.

Tabela 6 - Valor médio das exportações mundiais e gaúchas de fumo, em US\$, e participação do

Rio Grande do Sul nas exportações mundiais $(2001 / 2010)$

\begin{tabular}{l|c|c|c}
\hline & $\begin{array}{c}\text { PI - 2001 a } \\
\mathbf{2 0 0 4}\end{array}$ & $\begin{array}{c}\text { P II - 2005 a } \\
\mathbf{2 0 0 7}\end{array}$ & $\begin{array}{c}\text { P III - 2008 a } \\
\mathbf{2 0 1 0}\end{array}$ \\
\hline $\begin{array}{l}\text { Export. } \\
\text { Mundiais }\end{array}$ & 5.836 .363 .456 & 7.615 .823 .089 & 10.564 .458 .125 \\
$\begin{array}{l}\text { Export. } \\
\text { Gaúchas } \\
\text { Market } \\
\text { Share (\%) }\end{array}$ & 960.905 .424 & 1.413 .763 .062 & 1.905 .228 .518 \\
\hline
\end{tabular}

Fonte: Organização dos autores a partir de dados do Mdic Alice Web e Un Comtrade (2012).

Tabela 7 - Fontes de crescimento das exportações gaúchas de fumo (2001/2010)

\section{P II - P I P III - P II}

\begin{tabular}{lcc}
$\begin{array}{l}\text { Crescimento do } \\
\text { comércio mundial }\end{array}$ & 68.69 & 113.70 \\
$\begin{array}{l}\text { Destino das } \\
\text { exportações }\end{array}$ & -37.69 & -1.90 \\
Competitividade & 69.00 & -11.80 \\
\hline
\end{tabular}

Fonte: Organização dos autores a partir de dados do Mdic Alice Web e Un Comtrade (2012).

O resultado do efeito crescimento do comércio mundial pode ser explicado pelo aumento significativo das exportações mundiais de fumo ocorrido de 2005 a 2007, sendo o mesmo superior a $30 \%$ do período I $(2001 / 2004)$.

$\mathrm{O}$ efeito competitividade contribuiu com 69\% para explicar o comportamento das exportações de fumo do Rio Grande do Sul. Dentre os fatores que podem ter contribuído para esse efeito, destaca-se a Lei Kandir, a qual desonerou o Imposto sobre Circulação e Mercadorias (ICMS) sobre exportações de produtos básicos e semielaborados.

Outro importante fator é a disponibilidade de terras a preços baixos, de acordo com Machado et al. (2006), porém, mais importante que isso foram os investimentos em tecnologia. Concomitante a esses fatores, a maior parte da produção de fumo do país está concentrada no estado do Rio Grande do Sul, o qual possui terras férteis e de boa produtividade, o que o torna competitivo no setor.

$\mathrm{O}$ efeito destino das exportações refletiu negativamente nas exportações de fumo. Isso significa que as taxas de importação dos princi- 
pais mercados importadores cresceram a taxas menores que as importações mundiais, ou seja, o estado está direcionando as exportações de fumo para mercados menos dinâmicos que a média do comércio mundial.

b) período III em relação ao período II

O Rio Grande do Sul era responsável, no período II (2005/2007), por $18,56 \%$ das exportações mundiais de tabaco, mas, no período seguinte, diminuiu sua participação para $18,03 \%$ de acordo com a Tabela 6.

Quando analisada a decomposição das fontes de crescimento, do período III $(2008 / 2010)$ em relação ao período II, o efeito crescimento do comércio mundial foi o principal fator explicativo das exportações gaúchas de fumo, com 113,7\%. As exportações mundiais de fumo aumentaram cerca de $38 \%$ do período II para o período III, ao passo que as exportações gaúchas cresceram em torno de $34 \%$, no mesmo período. A participação positiva deste efeito contribuiu para minimizar as perdas geradas pelos outros efeitos negativos.

O efeito destino das exportações, apesar de continuar negativo, foi consideravelmente baixo, em valor absoluto, o que pode estar relacionado ao fato de que, do período III em relação ao período II, as importações mundiais de fumo cresceram $40 \%$, ao passo que as do principal mercado importador do Rio Grande do Sul, a União Europeia, cresceram 19\%. Isso significa que as taxas de importação dos principais mercados importadores cresceram a taxas menores que as importações mundiais.

$\mathrm{O}$ efeito competitividade reduziu sua importância, pois se observa uma queda significativa nesse efeito em relação ao período anterior, tornando-o negativo a $11,8 \%$. Isto pode estar relacionado ao fato de que o Brasil vem perdendo espaço para alguns países da África, e um dos motivos que trouxe grandes dificuldades para o setor foi a taxa cambial, o que elevou o preço do tabaco, tornando-se um dos mais caros do mundo.

\subsection{Decomposição das fontes de crescimento das carnes}

a) Período II em relação ao período I

A participação média do Rio Grande do Sul no total mundial comercializado de carnes (neste estudo constituído por carne bovina, suína e de frango), conforme a Tabela 8 , foi de $1,5 \%$ no período I (2001/2004), passando para $2,45 \%$ no período II (2005/2007), perfazendo um aumento de $0,95 \%$. Concomitantemente a esse aumento, pode ser observado um crescimento das exportações gaúchas em todos os períodos. Vale destacar o expressivo crescimento das exportações do período I para o período II, que foi de, aproximadamente, $159 \%$, atingindo um montante de US\$ 827 milhões comercializados, quase três vezes mais que o período anterior. Neste sentido, o aumento da participação do estado no comércio mundial pode ser confirmado.

Tabela 8 - Valor médio das exportações mundiais e gaúchas de carnes, em US\$, e participação do Rio Grande do Sul nas exportações mundiais (2001/2010)

\begin{tabular}{l|c|c|c}
\hline & $\begin{array}{c}\text { PI - 2001 a } \\
\mathbf{2 0 0 4}\end{array}$ & $\begin{array}{c}\text { P II - 2005 a } \\
\mathbf{2 0 0 7}\end{array}$ & $\begin{array}{c}\text { P III - 2008 a } \\
\mathbf{2 0 1 0}\end{array}$ \\
\hline $\begin{array}{l}\text { Export. } \\
\text { Mundiais }\end{array}$ & 21.314 .011 .642 & 33.754 .168 .861 & 44.578 .182 .714 \\
$\begin{array}{l}\text { Export. } \\
\text { Gaúchas }\end{array}$ & 319.472 .914 & 827.713 .035 & 1.191 .158 .686 \\
$\begin{array}{l}\text { Market } \\
\text { Share (\%) }\end{array}$ & 1.50 & 2.45 & 2.67 \\
\hline
\end{tabular}

Fonte: Organização dos autores a partir de dados do Mdic Alice Web e Un Comtrade (2012).

A decomposição das fontes de crescimento das carnes, do período II em relação ao período I, de acordo com a Tabela 9 , indicou valores positivos para os efeitos crescimento do comércio mundial e competitividade. Sendo que o efeito destino das exportações apresentou valor negativo. Esses resultados mostram que o estado mantém sua posição competitiva no mercado internacional.

Tabela 9 - Fontes de crescimento das exportações gaúchas de carnes (2001/2010)

\begin{tabular}{lcc}
\hline & P II - P I & P III - P II \\
$\begin{array}{l}\text { Crescimento do } \\
\text { comércio mundial }\end{array}$ & 57.48 & 473.84 \\
$\begin{array}{l}\text { Destino das } \\
\text { exportações }\end{array}$ & -37.43 & -373.03 \\
Competitividade & 80.00 & -0.80 \\
\hline
\end{tabular}

Fonte: Organização dos autores a partir de dados do Mdic Alice Web e Un Comtrade (2012).

O efeito crescimento do comércio mundial pode estar relacionado ao crescimento das exportações deste setor, do período I (2001/2004) para o período II (2005/2008). Um dos fatores que pode estar relacionado ao aumento desse efeito é que os maiores importadores mundiais de carne in natura, a UE e a Rússia, embora adotem exigências sanitárias, segundo Rubin, Ilha e Waquil (2008), são as mais abertas e não impedem a 
entrada do produto.

O efeito competitividade foi o principal impulsionador das exportações gaúchas, conseguindo elevar seu Market-share em 0,95\% do período I para o período II. Este efeito pode estar relacionado ao cancelamento do embargo à carne gaúcha pela Rússia, em abril de 2006, e sua manutenção para outros estados, inclusive Santa Catarina, o maior produtor/exportador de carne suína, que segundo Furstenau (2007), alavancaram as vendas gaúchas dessa carne para aquele país, que compra do Brasil $65 \%$ das suas importações dessa carne.

O efeito negativo do destino das exportações indica que o estado concentrou suas vendas em mercados menos dinâmicos, ao invés de destiná-las a países com crescimento nas importações acima da média mundial.

b) período III em relação ao período II

O aumento da participação média do Rio Grande do Sul no total mundial comercializado de carnes pode ser novamente confirmado, sendo que apresentou uma variação menor do que do período I para o II, porém, passou de $2,45 \%$ do período II $(2005 / 2007)$ para $2,67 \%$ no período III $(2008 / 2010)$, conforme Tabela 8. Da mesma forma, pode ser observado um crescimento das exportações gaúchas de aproximadamente $44 \%$, chegando a US\$ 1,1 bilhões comercializados.

A decomposição das fontes de crescimento das carnes, do período III em relação ao período II, de acordo com a Tabela 9, mostra que o efeito crescimento do comércio mundial foi o principal fator explicativo das exportações de carnes, com $473,84 \%$, e o efeito destino das exportações reduziu significativamente para $-373.03 \%$. Já a competitividade refletiu negativamente nas exportações gaúchas de carnes. Assim, verifica-se que houve uma forte queda nesse efeito em relação ao período anterior.

O efeito crescimento do comércio mundial continuou positivo, mas aumentou significativamente, fato que pode estar relacionado ao crescimento de aproximadamente $32 \%$ das exportações mundiais do período III em relação ao período II.

Ao analisar o efeito destino das exportações, observa-se que ele continua negativo, no entanto, o valor absoluto aumentou em grande proporção. Isso indica o baixo dinamismo de mercado, ou seja, o Rio Grande do Sul continuou direcionando suas exportações para mercados menos dinâmicos que a média do comércio mundial.

A queda do efeito competitividade pode estar relacionada à intensificação na fiscalização da qualidade dos produtos (as certificações), visto que, de acordo com Rubin, Ilha e Waquil (2008), o item que mais condiciona a ampliação das exportações diz respeito às barreiras impeditivas, afetando negativamente a competitividade e o grau de eficiência junto a terceiros mercados.

\section{CONCLUSÕES}

Neste estudo, constatou-se que o Rio Grande do Sul desempenha um papel importante para o comércio exterior. A participação do estado nas exportações mundiais de soja em grão, fumo e carnes vem elevando o seu Market-share ao longo dos anos. O estado destaca-se como o quarto maior produtor e exportador de produtos agropecuários do Brasil.

No entanto, para continuar com esse desempenho significativo, o estado precisa superar vários entraves internos como redução dos custos de transporte e logística, melhores condições de infraestrutura e maiores investimentos em pesquisa, assim como buscar alternativas junto à Organização Mundial do Comércio (OMC) para a redução das barreiras tarifárias e não tarifárias que os principais importadores impõem ao agronegócio.

A aplicação do modelo Constant-Market-Share permitiu indicar quais os fatores que mais influenciaram as exportações de soja em grão, fumo e carnes. Diante disso, vale destacar que não se podem afirmar de maneira discriminada quais os fatores que influenciaram o efeito competitividade, uma vez que este é residual no modelo.

Diante das análises das fontes de crescimento das exportações gaúchas de soja em grão, fumo e carnes, pode-se observar que, do período II em relação ao período I, o efeito crescimento do comércio mundial foi o que mais colaborou nas exportações da soja em grão, enquanto que, para o fumo e as carnes, o efeito competitividade foi o mais significativo. Entretanto, as análises do período III em relação ao período II mostram que o efeito competitividade caiu significativamente, sendo que o efeito crescimento do comércio mundial foi o que mais contribuiu para as exportações de soja em grão, fumo e carnes. Já o efeito destino das exportações foi positivo apenas para as exportações de soja em grão, do período III em relação ao período II, mas, de certa forma, não foi o efeito que mais colaborou para as exportações.

O efeito crescimento do comércio mundial, fator que mais contribuiu nas exportações do último 
período, pode estar relacionado ao aumento do fluxo de comércio internacional, devido a vários fatores como o aumento da demanda chinesa, assim como os estoques ajustados dos Estados Unidos, que acabaram impulsionando as exportações brasileiras dos produtos do agronegócio. A queda do efeito competitividade de um período para o outro pode ter sido influenciada principalmente pela sobrevalorização cambial nos anos de 2004, assim como a intensificação da fiscalização sanitária e a as barreiras tarifárias e não tarifárias impostas pelos principais importadores.

A partir deste trabalho, vários outros aspectos podem ser analisados tais como estudos mais avançados sobre a identificação de fatores relacionados à competitividade do agronegócio gaúcho, bem como simular cenários, através de modelos de Equilíbrio Geral Computável e de Alocação Espacial, os quais apontem os ganhos que o país poderá ter na perspectiva de quedas das barreiras tarifarias e não tarifárias que os principais mercados importadores impõem às exportações do agronegócio do RS.

\section{REFERÊNCIAS}

ASSOCIAÇÃO BRASILEIRA DA INDÚSTRIA PRODUTORA E EXPORTADORA DE CARNE SUÍNA (ABIPECS). Disponível em: http://www. abipecs.com.br/. Acesso em: 12 de novembro de 2012.

AREND, S. C.; BEGNIS, H. S. M.; ALIEVI, R. M. Oportunismo e quebra de contratos na cadeia produtiva do tabaco no Sul do Brasil: uma avaliação econométrica. In: CONGRESSO BRASILEIRO DE ECONOMIA E SOCIOLOGIA RURAL, 50., 2012, Vitória. Anais... Vitória: SOBER, 2012.

CARVALHO, F. M. A. O comportamento das exportações brasileiras e a dinâmica do complexo agroindustrial. 1995. Tese Doutorado em Economia Aplicada - Escola Superior de Agricultura "Luiz de Queiroz", Universidade de São Paulo, São Paulo, 1995.

CARVALHO F. M. A. A dinâmica agroexportadora brasileira: mudança estrutural, vantagem comparativa e fontes de crescimento. Revista de Economia e Sociologia Rural, v. 35, n. 1, p. 9-44, 1997.

COMPANHIA NACIONAL DE ABASTECIMENTO (CONAB). Acompanhamento da Safra
Brasileira: Grãos, safra 2011/2012. Quarto Levantamento, Brasília, jan/2012. 38p. Disponível em: http://www.conab.gov.br/OlalaCMS/uploads/arqu ivos/12_01_10_10_53_02boletim_graos_4o_levantamento.pdf. Acesso em: 29 de outubro de 2012.

CORONEL, D. A.; MACHADO, J. A. D.; CARVALHO, F. M. A. Fontes de crescimento das exportações do complexo soja brasileiro. Análise Revista Científica de Administração, Contabilidade e Economia. v. 19. n. 2. p. 62-77, 2008.

CORRÊA, A. Crise muda perfil das exportações brasileiras. Disponível em: http://www.bbc.co.uk/ portuguese/noticias/2009/09/090908_crise_exportacoes_ac_np.shtml. Acesso em: 30 nov 2012.

FEDERAÇÃO DA AGRICULTURA DO ESTADO DO RIO GRANDE DO SUL (FARSUL). Disponível em: http://www.farsul.org.br/. Acesso em: 30 nov 2012.

FIGUEIREDO, A. M.; SANTOS, M. L.; LÍRIO, V. S. Análise de Maket Share e fontes de variação das exportações brasileiras de soja. Revista de Economia e Agronegócio. v.2. n. 3. p. 335-360, 2004.

FUNDAÇÃO DE ECONOMIA E ESTATÍSTICA (FEE). Indicadores econômicos. 2012. Disponível em: http://revistas.fee.tche.br/index.php/indicadores. Acesso em: 29 de outubro de 2012.

FURSTENAU, V. Exportações de carne: um segmento extremamente dinâmico no Brasil. Indicadores Econômicos FEE. v. 34, n. 4, p. 63-72, 2007.

\section{LEAMER, E. E; STERN, R. M. Quantitative} international economics. Chicago: Allyn and Bacon, 1970.

MALAFAIA, G. C.; BARCELLOS, J. O. J. Sistemas agroalimentares locais e a visão baseada em recursos: construindo vantagens competitivas para a carne bovina gaúcha. Revista de Economia e Agronegócio. v.5. n. 1. p. 25-50, 2007.

MACHADO, L. V. N.; AMIN, M. M.; CARVALHO, F. M. A.; SANTANA, A. C. Análise do desempenho das exportações brasileiras de carne bovina: uma aplicação do método Constant Market Share, 19952003. Revista de Economia e Agronegócio. v.4. n. 2. p. 195-218, 2006.

MINISTÉRIO DA AGRICULTURA, PECUÁRIA 
E ABASTECIMENTO (MAPA). Agronegócio. Disponível em: http://www.agricultura.gov.br. Acesso em: 29 de outubro de 2012.

MINISTÉRIO DO DESENVOLIMENTO INDÚSTRIA E COMERCIO EXTERIOR (MIDIC). Secretaria de Comércio Exterior (SECEX). Disponível em: http://www. desenvolvimento.gov.br/sitio/interna/ interna.php?area $=5 \&$ menu $=1078 \&$ refr $=1076$.

Acesso em: 12 de novembro de 2012.

RIGAUZ. L. R. Market Share analysis aplied to canadian wheat exports. Canadian Journal of Agricultural Economics, Orleans, v. 19, n. 1, p. 22-23, Jul. 1971.

RUBIN, L. S.; ILHA, A. S.; WAQUIL, P. D. O comércio potencial brasileiro de carne bovina no contexto de integração regional. Revista de Economia e Sociologia Rural. v. 46, n. 04, p. 1067-1094, out/dez 2008.

SILVA, F. A.; GOMES, M. F. M.; CORONEL, D. A.; GOMES, M. T. M. Competitividade das exportações brasileiras de mamão, 1995 a 2008. Revista de Economia e Sociologia Rural, v. 9, n. 3, p. 393-420, 2011.a.

SILVA, M. A. P.; ROSADO, P. L.; BRAGA, M. J.; CAMPOS, A. C. Oferta de exportação de carne de frango do Brasil, de 1992 a 2007. Revista de Economia e Sociologia Rural, v. 49, n. 1, p. 31-54, 2011.b.

SOUZA, S. S. Mudanças cambiais e o efeito dos fatores de crescimento das receitas de exportações brasileiras de soja. Revista de Economia e Agronegócio, Viçosa, v. 5, n. 1, p. 1-24, jan./mar. 2007. 